\title{
Argon laser photocoagulation of symptomatic flap tears and retinal breaks of fellow eyes
}

\author{
A. POLLAK AND M. OLIVER \\ From the Department of Ophthalmology, Kaplan Hospital, Rehovot, Israel, affiliated to the \\ Medical School of the Hebrew University and Hadassah, Jerusalem
}

SUMmARY A series of 95 eyes (93 patients) with retinal breaks, high-risk candidates for rhegmatogenous retinal detachment, were treated prophylactically with argon laser photocoagulation (ALP). Group A comprised 74 eyes with flap symptomatic tears. In 28 of these (subgroup A (1)) the size of the tear was smaller than 1 disc diameter and greater than $1 / 3$ disc diameter. In 46 eyes (subgroup A (2)) the size of the tear was at least 1 disc diameter but not greater than 3 disc diameters. Group B comprised 21 fellow eyes with 34 retinal breaks in patients who had retinal detachment in the other eye. One patient of subgroup A (1) developed a rhegmatogenous retinal detachment 6 days after ALP treatment. One patient of group B developed a retinal detachment after cataract extraction. This detachment was unrelated to the previously treated retinal break. In the series of group A the mean follow-up period was 27.8 months. From previously reported follow-up data it is probable that at least in the case of flap symptomatic tears our results can be considered conclusive. There were no complications related to the prophylactic treatment of dangerous retinal breaks with ALP. This form of treatment is accurate, easy to use, and comfortable for the patient. ALP would appear to be superior to xenon arc photocoagulation and cryopexy.

Different types of treatment have been used for the prophylaxis of rhegmatogenous retinal detachment. ${ }^{12}$ The first were cautery and diathermy, ${ }^{1}$ which met with little acclaim and were replaced in the 1950s by the extensively used xenon arc photocoagulation. ${ }^{3-5}$ Cryopexy was the next most popular surgical technique. ${ }^{67}$ In the late 1960 Z Zweng $^{8}$ reported the use of argon laser photocoagulation (ALP) for retinal breaks. The advantages and disadvantages of cautery, diathermy, xenon arc photocoagulation, and cryopexy have been well documented..$^{4-11}$ However, we do not know of any extended follow-up studies on the results, advantages, or complications of ALP.

In this report an evaluation is made of the results of treatment of retinal breaks with ALP in a series of 95 eyes of 93 patients who were diagnosed as very likely to develop retinal detachment. The term 'break' refers to a full-thickness defect of the retina.

\section{Material and methods}

The clinical data of all the patients with retinal holes Correspondence to M Oliver, MD, Kaplan Hospital, 76-100 Rehovot, Israel. treated prophylactically with ALP from January 1975 to June 1980 were reviewed. The patients were consecutive cases who fulfilled the criteria according to which the following 2 groups were defined.

\section{GROUP A (Table 1)}

This group comprised only patients with flap symptomatic tears. A 'symptomatic tear' is a break caused by vitreous traction in the eye of a patient complaining of flashes and/or entopsias. Two subgroups were defined by size of tear.

Subgroup A (1) comprised 28 eyes of 28 patients. The size of tear was greater than $1 / 3$ disc diameter and smaller than 1 disc diameter. None of the patients was aphakic. In 4 eyes of subgroup A (1) there were more than a single break. Thus the total was 35 tears.

Subgroup A (2) comprised 46 eyes of 44 patients. The size of tear in this group was 1 disc diameter or more, but not greater than 3 disc diameters. In 13 eyes more than 1 tear was found. The total number of breaks in subgroup A (2) was 65 . Two eyes in subgroup A (2) were aphakic. One patient in this group had had 2 separate episodes of visual complaints, and in each of them a new symptomatic tear was found. 
Table 1 The number of patients, eyes, and breaks in groups $A$ and $B$

\begin{tabular}{lllll}
\hline & $\begin{array}{l}\text { No. of } \\
\text { patients }\end{array}$ & $\begin{array}{l}\text { No. of } \\
\text { eyes }\end{array}$ & $\begin{array}{l}\text { No. of } \\
\text { breaks }\end{array}$ & $\begin{array}{l}\text { No. of eyes } \\
\text { with more than } \\
\text { a single break }\end{array}$ \\
\hline Subgroup A (1) & 28 & 28 & 35 & 4 \\
Subgroup A (2) & 44 & 46 & 65 & 13 \\
Group B & 21 & 21 & 34 & 9 \\
\hline
\end{tabular}

Table 2 Symptoms and findings as found on the first eye examination

\begin{tabular}{lrrrrr}
\hline & Photopsiae Entopsiae & $\begin{array}{l}\text { Reduced } \\
\text { vision }\end{array}$ & $\begin{array}{l}\text { Localised } \\
\text { retinal } \\
\text { detach- } \\
\text { ment }\end{array}$ & $\begin{array}{l}\text { Vitreous } \\
\text { haemor- } \\
\text { rhage }\end{array}$ \\
\hline Subgroup A (1) & 4 & 23 & 8 & 6 & 16 \\
Subgroup A (2) & 10 & 28 & 22 & 22 & 32 \\
Group B & - & 2 & 1 & 4 & - \\
\hline
\end{tabular}

In all the patients of group $A$ with more than 1 tear in the treated eye (4 patients in subgroup A (1) and 13 patients in subgroup $A(2))$ the symptomatic tear was determined by 1 or more of the following: vitreous haemorrhage, vitreous traction on the flap of the tear, lattice changes on the flap, localised retinal detachment, retinal haemorrhage at the side of the tear. All the tears in these 17 eyes were treated prophylactically.

\section{GrouP B (Table 1)}

This group comprised 21 eyes of 21 patients with retinal detachment in one eye and one or more retinal breaks in the fellow eye. Five eyes were aphakic. Nine patients had more than 1 break. The total was 34 breaks. Twenty-five breaks were smaller than 1 disc diameter and 9 were greater. Two patients of group B had a symptomatic flap tear. There were 8 asymptomatic flap tears. Six breaks were located in areas of lattice degeneration.

Table 2 summarises the symptoms and findings for the patients of all the groups.

After dilatation of the pupil with $0.5 \%$ tropicamide and $10 \%$ phenylephrine hydrochloride treatment was given with slit-lamp delivery argon laser photocoagulation, the Goldmann 3-mirror diagnostic contact lens being used. The most frequently used photocoagulator parameters were 200 to $500 \mu \mathrm{m}$ beam diameter, $0 \cdot 1$ to $0.5 \mathrm{~s}$ time exposure, and 600 to $1200 \mathrm{~mW}$ power. Some variations of the parameters were made, depending on the amount of reaction, so as to obtain a moderately heavy to heavy lesion. The break was surrounded with at least 3 rows of photocoagulation marks. Two types of breaks could not be completely surrounded with photocoagulation marks, namely, breaks extending anteriorly as far as the ora serrata, and flap tears with a localised retinal detachment adjacent to the anterior margin of the tear, making a total of 14,6 in subgroup $A(1)$ and 8 in subgroup A (2). A U-shaped photocoagulation was performed in these breaks, and care was taken to extend the treated area at the anterior edges sideways for at least 5 rows of photocoagulation marks and whenever possible to the ora serrata.

In all cases we took great care to place the lesions in areas in which the sensory retina and pigment epithelium were-not separated.

\section{Results}

Group A. Only 1 eye in this group of 74 eyes developed retinal detachment, in a patient in subgroup $A$ (1) who was examined for the first time because of entoptic complaints. A flap tear smaller than 1 disc diameter was found in the superior temporal quadrant. ALP was performed the same day. Six days later a retinal detachment was seen in the upper and lower temporal quadrants, not extending to the macula. Surgery for retinal detachment was successful, and after a follow-up period of $2 \frac{1 / 2}{2}$ years the retina was flat and visual acuity $6 / 12$.

The mean follow-up period after treatment of this group of patients was $27 \cdot 8$ months, the shortest period being 6 months and the longest 6 years.

Group B. Thirty-four breaks were treated in this group of patients. Only 1 patient in this group of 21 fellow eyes developed retinal detachment, which, however, was not related to a previously photocoagulated flap tear.

The mean follow-up period after treatment in this group was 31.6 months, the shortest period being 10 months and the longest 6 years.

\section{Discussion}

In 1972 Zweng reported on the studies that he, Campbell, L'Esperance, and Aiello had carried out with ruby laser and ALP in retinal breaks. ${ }^{8}$ Their combined study of 2000 cases treated with ruby laser and 215 treated with argon laser showed a high success-rate for the prevention of retinal detachment. Moreover, the incidence of complications was markedly reduced in comparison with cases treated with xenon arc photocoagulation. 1400 of the 2000 patients treated with ruby laser had associated retinal detachment, as had 150 of the 215 patients treated with argon laser. No data were given by Zweng ${ }^{8}$ as regards the nature, size, location, and associated symptomatology of treated retinal breaks.

In our study 74 eyes with flap symptomatic tears 
were treated with ALP. Of these, 28 eyes had breaks from $1 / 3$ to 1 disc diameter and 46 eyes had larger ones. In this last group 13 eyes had more than 1 flap horseshoe tear. In 48 eyes vitreous haemorrhage was present when the break was found and in 28 eyes there was localised retinal detachment. Thus all 74 eyes in this group were high-risk candidates for retinal detachment, but only 1 developed it. We cannot explain this single failure of ALP preventive treatment. The size of the tear, the amount of vitreous pulling, and the haemorrhage were relatively mild in comparison with many of the cases in subgroup A (2). Moreover no subclinical retinal detachment was observed when ALP was administered. Nevertheless these 74 eyes with symptomatic flap tears treated prophylactically compare favourably with the untreated cases described by Colyear and Pischel, ${ }^{12}$ Neumann et al. ${ }^{13}$ and Davis. ${ }^{14}$ Colyear and Pischel ${ }^{12}$ described 9 retinal detachments in 10 patients with untreated flap symptomatic tears. Six out of 24 symptomatic flap tears followed-up by Neumann developed retinal detachment, and Davis reported 9 similar cases in a series of 25 patients.

The incidence of patients with retinal detachment in one eye who develop detachment in their fellow eye is much higher $(11 \%)$ than that of retinal detachment $(0.009 \%)$ in the general population. ${ }^{15-18}$ Davis et al. ${ }^{15}$ reported an incidence of $16 \%$ of such cases, with a flap tear in the fellow eye, and Hyams described 32 , of whom 10 later developed retinal detachment in the other eye. There is good evidence that prophylactic treatment of retinal breaks in similar cases is beneficial. In a study performed in Israel prophylactic treatment of retinal breaks in fellow eyes reduced the incidence of retinal detachment from $11 \%$ to $3 \% .{ }^{18}$ Group B in this study comprised 21 patients with retinal detachment in one eye, treated prophylactically with ALP for 1 or more breaks in the second eye, of whom only 1 developed retinal detachment in the fellow eye, but unrelated to the break treated with ALP. It appeared 1 month after cataract extraction, the photocoagulated retina remained flat, and good chorioretinal scars were seen around the original tear.

Fourteen flap tears (6 in subgroup A (1) and 8 in subgroup A (2)) were not surrounded completely with ALP lesions but were treated by a modified technique in a U-shaped pattern, necessitated by the extreme anterior location of the tear with or without a localised retinal detachment at the anterior margin. All these patients, especially the 8 in subgroup A (2), were high-risk candidates for retinal detachment, but none of them developed it. Thus, this group of 14 patients does not seem to support the widely accepted opinion $^{1920}$ that the anterior aspect of the hole is by far the most important part to seal, as this is the area that is most subjected to vitreous traction. It is our impression that in similar cases retinal detachment can be prevented by photocoagulating a broader area of unseparated retina at the side borders of the tear.

Colyear and Pischel $^{12}$ stated that in cases of symptomatic retinal tears detachment appears at the latest 2 weeks after the onset of the symptoms, but that if the retina remains flat during this period it is very unlikely that detachment will occur. In Davis's series $^{14}$ of similar cases the critical period for the appearance of retinal detachment was stated as 6 weeks. From these 2 reports we can assume that the present results for ALP preventive treatment of the patients in group A may well be conclusive, since the mean follow-up period was 27.8 months and none was followed up for a period shorter than 6 months.

No complications related to the ALP treatment were found in this series, which is particularly significant if one compares ALP to cryopexy and xenon arc photocoagulation. Cibis ${ }^{21}$ found that 2 to $3 \%$ of patients treated with xenon arc photocoagulation develop preretinal macular membranes and macular pucker. These complications occur also after treatment with diathermy and cryopexy. Exudative retinal detachment has been described after cryopexy. ${ }^{22}$ Vitreous damage is a well-known and sometimes serious complication of cryopexy and xenon arc photocoagulation. These complications were never seen in this series of cases treated with ALP. The importance of avoiding additional damage to a diseased vitreous cannot be overemphasised in the prevention of retinal detachment.

Very frequently cryopexy has to be used under surgical conditions, with complete asepsis, conjunctival incision, and suturing. The patient's discomfort is considerable and treatment may include admission to hospital, whereas the treatment with ALP is simple. It is ambulatory and causes minimal discomfort. ALP is delivered by binocular and direct viewing of the treated area. It is highly accurate in localisation, and its intensity can be easily adjusted according to individual tissue reaction.

ALP is a safe and reliable technique for the treatment of symptomatic flap tears and other high-risk retinal breaks. Strong vitreous traction at the edge of the break, and retinal and vitreous haemorrhages related to the appearance of the break, did not appear to lessen the favourable results in this series. It is probable that cryopexy should be reserved for cases which cannot be treated with ALP because of technical difficulties such as opaque media, small and nonreactive pupils, and unsatisfactory tissue response. It is also possible that the employment of ALP may be limited by the size of the retinal break. The largest retinal break treated by us was 3 disc diameters in size. Whether larger breaks can be treated safely with ALP has yet to be investigated. 


\section{References}

1 Preventive treatment of idiopathic and secondary retinal detachment: panel discussion. Chairman, Weve, HJM. XVIII Concilium Ophthalmologicum 1958 Belgica. Brussels: Imprimerie Médicale et Scientifique, SA, 1958; 1: 965-1050.

2 Morse PH, Scheie HG. Prophylactic cryoretinopexy of retinal breaks. Arch Ophthalmol 1974; 92: 204-7.

3 Colyear BH, Pischel DK. Preventive treatment of retinal detachment by means of light coagulation. Trans Pac Coast Otoophthalmol Soc 1960; 41: 193-215.

4 Okun E, Cibis PA. Photocoagulation in limited retinal detachment and breaks without detachment. In: McPherson A, ed. New and Controversial Aspects of Retinal Detachment. New York: Paul B. Hoeber, 1968: 164-72.

5 Mortimer CB. The prevention of retinal detachment. Can J Ophthalmol 1966; 1: 206-12.

6 Tasman W, Jaegers KR. A retrospective study of xenon photocoagulation and cryotherapy in the treatment of retinal breaks. In; Pruett RC, Regan CDJ, eds. Retina Congress. New York: Appleton-Century-Crofts, 1972: 557-64.

7 Kreissig I, Sbaiti A. Kryopexie in der Ablatio-Prophylaxe. Klin Monatsbl Augenheilkd 1971; 159: 558-96.

8 Zweng HC. Laser photocoagulation in rhegmatogenous retinal separation. In: Pruett RC, Regan CDJ, eds. Retina Congress. New York, Appleton-Century-Crofts, 1972: 551-4.

9 Colyear BH. Discussion of Byer NE, Colyear BH: New retinal tears following photocoagulation. Trans Pac Coast Otoophthalmol Soc 1965; 46: 257-9.

10 Byer NE. Lattice degeneration of the retina. Surv Opthalmol 1979; 23: 213-47.

11 Boniuk I, Okun E, Johnston GP, Arribas N. Xenon photocoagulation versus cryotherapy in the prevention of retinal detachment. Mod Probl Ophthalmol 1974; 12: 81-92.
12 Colyear BH, Pischel DK. Clinical tears in the retina without detachment. Am J Ophthalmol 1956; 41: 773-93.

13 Neumann E, Hyams S, Barkai S, et al. Natural history of retinal holes with specific reference to the development of retinal detachment and the time factor involved. In: Michaelson IC, Berman ER, eds. Causes and Prevention of Blindness. New York, London: Academic Press, 1972: 404-8.

14 Davis MD. The natural history of retinal breaks. Arch Ophthalmol 1974; 92: 183-94.

15 Davis MD, Segal PP, MacCormack A. The natural course followed by the fellow eye in patients with rhegmatogenous retinal detachment. In: Pruett RC, Regan CDJ, eds. Retina Congress. New York: Appleton-Century-Crofts, 1972: 643-60.

16 Hyams SW, Meir E, Ivry M, et al. Chorioretinal lesions predisposing to retinal detachment. Am J Ophthalmol 1974; 78: 429-37.

17 Merin S, Feiler V, Hyams S, et al. The fate of the fellow eye in retinal detachment. Am J Ophthalmol 1971; 71:477-81.

18 Stein R, Feiller-Ofry V, Romano A. The effect of treatment in the prevention of retinal detachment. In: Michaelson IC, Berman ER, eds. Causes and Prevention of Blindness. New York, London: Academic Press, 1972: 409-10.

19 Robertson DM, Norton EWD. Long-term follow up of treated retinal breaks. Am J Ophthalmol 1973; 75: 395-414.

20 Sigelman J. Vitreous base classification of retinal tears: clinical application. Surv Ophthalmol 1980; 25: 59-74.

21 Cibis PA. Limits and hazards of photocoagulation. Trans Am Acad Ophthalmol Otolaryngol 1962; 66: 71.

22 Aaberg TM, Pawlowski GJ. Exudative retinal detachments following scleral buckling with cryotherapy. Am J Ophthalmol 1972; 74: 245-9. 